\title{
Reactive Oxygen Species Production by Quercetin Causes the Death of Leishmania amazonensis Intracellular Amastigotes
}

\author{
Fernanda Fonseca-Silva, ${ }^{\dagger}$ Job D. F. Inacio, ${ }^{\dagger}$ Marilene M. Canto-Cavalheiro, and Elmo E. Almeida-Amaral*
}

Laboratório de Bioquímica de Tripanosomatideos, Instituto Oswaldo Cruz, Fundação Oswaldo Cruz, Pavilhão Leônidas Deane, Manguinhos, 21045-900, Rio de Janeiro, Rio de Janeiro, Brazil

ABSTRACT: The present study reports the mechanism of the antileishmanial activity of quercetin (1) against the intracellular amastigote form of Leishmania amazonensis. Treatment with $\mathbf{1}$ reduced the infection index in L. amazonensis-infected macrophages in a dose-dependent manner, with an $\mathrm{IC}_{50}$ value of $3.4 \mu \mathrm{M}$ and a selectivity index of 16.8, and additionally increased ROS generation also in a dose-dependent manner. Quercetin (1) has been described as a pro-oxidant that induces the production of reactive oxygen species, which can cause cell death. Taken together, these results

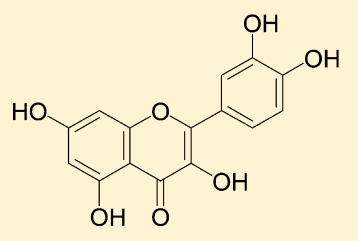

1

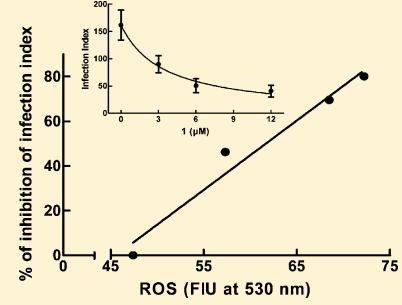
suggest that ROS production plays a role in the mechanism of action of $\mathbf{1}$ in the control of intracellular amastigotes of $L$. amazonensis.

$\mathrm{L}$ eishmaniasis is a parasitic disease caused by protozoa of the genus Leishmania that may lead to extensive mortality and morbidity. Leishmaniasis is endemic in 88 countries, mainly in tropical and subtropical areas, and it affects more than 12 million people worldwide. ${ }^{1}$ Leishmania amazonensis is the etiological agent of cutaneous or diffuse cutaneous lesions and can also induce the complete clinical spectrum of leishmaniasis, including visceral infection.

Several drug screenings of natural compounds have been successful in identifying novel compounds for treating certain parasitic diseases. Both plant extracts and pure compounds, including some types of flavonoids, have been reported to possess significant antiprotozoal activities. ${ }^{2,3}$ Quercetin (1) is the most common flavone in the human diet. This compound has a wide range of reported biological effects, including antioxidant, antihypertensive, anti-inflammatory, antimicrobial, and antiprotozoal activities. ${ }^{4,5}$ Additionally, compound $\mathbf{1}$ can induce the production of superoxide anions, hydrogen peroxide, and other reactive oxygen species (ROS). ${ }^{6-8}$<smiles>O=c1c(O)c(-c2ccc(O)c(O)c2)oc2cc(O)cc(O)c12</smiles>

Quercetin (1)

ROS are generated by cells that are infected with pathogens as a mechanism to combat the infection. ROS can also be generated in response to some drugs, and this is a basic mechanism through which certain antiprotozoal drugs act to kill parasites within an infected cell. The ability of a drug to generate ROS to destroy cellular macromolecular components is important because this action can be exploited to achieve the maximal effect of an antiparasitic drug.

One example of the biological activity of quercetin (1) is its effect on the bloodstream parasite Trypanosoma brucei and amastigotes of Leishmania donovani. ${ }^{9,10}$ To determine the effect of quercetin (1) on intracellular amastigotes of L. amazonensis, L. amazonensis-infected macrophages were incubated in the presence or absence of $1(3,6$, and $12 \mu \mathrm{M})$ for $72 \mathrm{~h}$. Compound 1 reduced the infection index in a dose-dependent manner $(p<0.05)$, with an $\mathrm{IC}_{50}$ value of $3.4 \mu \mathrm{M}$ (Figure 1a). The antileishmanial potency of $\mathbf{1}$ was similar to that of miltefosine, which has already been used successfully for the treatment of New World leishmaniasis ${ }^{11}$ and has an $\mathrm{IC}_{50}$ value of $3.2 \mu \mathrm{M}$ at $72 \mathrm{~h}$ for L. amazonensis. ${ }^{12}$ Quercetin (1) inhibited the growth of L. amazonensis by $74.8 \%$ after $72 \mathrm{~h}$ at the highest dose tested $(12 \mu \mathrm{M})$.

Notably, the concentrations of $\mathbf{1}$ employed in this assay had no cytotoxic effects on the macrophages (Figure $1 \mathrm{~b}$ ). The $\mathrm{IC}_{50}$ value of 1 against macrophages was $80.2 \mu \mathrm{M}$, which correlates to a selectivity index of 16.8 . According to Weniger et al., the biological efficacy of a test compound is not attributable to general cytotoxicity when the selectivity index is $\geq 10{ }^{13}$ The present results demonstrate a specific antileishmanial activity of quercetin (1) against intracellular amastigotes of L. amazonensis.

Flavones such as $\mathbf{1}$ have been described as pro-oxidants because they generate ROS, which cause cell death in some cancer cells. ${ }^{6,14}$ The ROS levels were measured to investigate whether 1 promotes ROS production as a possible mechanism of inducing cell death in intracellular amastigotes. Quercetin (1) increased ROS generation after $72 \mathrm{~h}$ of treatment in $L$. amazonensis-infected macrophages in a dose-dependent manner

Received: March 6, 2013

Published: July 22, 2013 

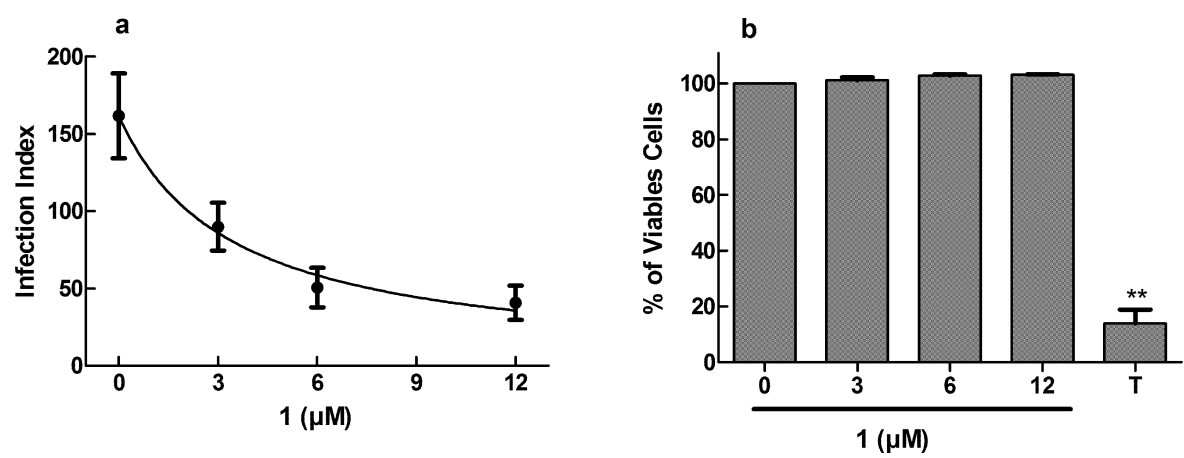

Figure 1. Effect of quercetin (1) on intracellular amastigotes (a) and the toxicity of $\mathbf{1}$ in peritoneal macrophages (b). Macrophages were infected with $L$. amazonensis promastigotes for $3 \mathrm{~h}$ at $37^{\circ} \mathrm{C}$ and then incubated in the absence or presence of $1(3,6$, and $12 \mu \mathrm{M})$ for $72 \mathrm{~h}$. The infection index was determined using light microscopy; at least 200 macrophages were counted on each coverslip in duplicate (panel a). Macrophages were incubated with the indicated concentration of $\mathbf{1}$ for $72 \mathrm{~h}$, and cell viability was measured using the AlamarBlue assay (panel b). The values shown represent the mean \pm standard error of three independent experiments. In the control samples (absence of $\mathbf{1}$ ), a similar volume of vehicle (DMSO $0.2 \%)$ was added to the cells. The positive control for reduced cellular viability (disrupted cells) was obtained by adding $0.1 \% \mathrm{Triton} \mathrm{X}-100(\mathrm{~T}=$ $0.1 \%$ Triton X-100). ** indicates a significant difference relative to the control group $(p<0.01)$.
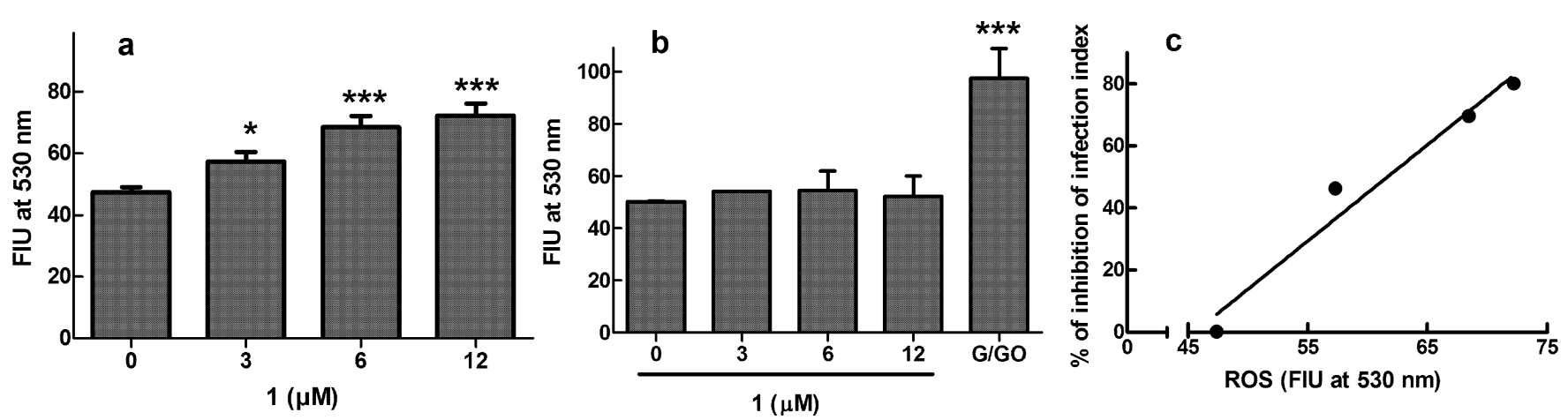

Figure 2. Quercetin-induced ROS production. L. amazonensis-infected macrophages (a) and uninfected macrophages (b) were incubated in the absence or presence of $1(3,6$, and $12 \mu \mathrm{M})$ for $72 \mathrm{~h}$. ROS generation was measured using the fluorescent dye $\mathrm{H}_{2} \mathrm{DCFDA}$ as described in the Experimental Section. Data are expressed in fluorescence intensity units (FIU). The values shown represent the mean \pm standard error of three independent experiments. A positive control was obtained by adding 20 units $/ \mathrm{mL}$ glucose oxidase $+60 \mathrm{mM}$ glucose for 30 min. * and *** indicate significant differences relative to the control (absence of 1$)(p<0.05$ and $p<0.001$, respectively). (c) Linear regression analysis was performed using GraphPad Prism $5\left(R^{2}=0.9636\right)$.

$(p<0.01)$ (Figure 2a) but did not increase ROS in uninfected macrophages (Figure $2 b$ ), suggesting that the increase in ROS could be specific to cells infected with intracellular amastigotes. The level of ROS was 1.5-fold higher in $12 \mu \mathrm{M}$ quercetintreated L. amazonensis-infected macrophages than in nontreated L. amazonensis-infected macrophages used throughout the experiment. A linear correlation $\left(R^{2}=0.9636\right)$ between the percent inhibition of the infection index and ROS production upon treatment with compound $\mathbf{1}$ was observed (Figure 2c). Since glucose oxidase catalyzes the oxidation of D-glucose and generates $\mathrm{H}_{2} \mathrm{O}_{2}$, this enzyme was employed as a positive control. Glucose/glucose oxidase led to increased ROS levels when compared with those of the control (1.9-fold compared with the level of ROS in the nontreated L. amazonensis-infected macrophages).

ROS are generated in cells as a means to fight pathogenic infections. ROS can also be generated in response to some drugs, which is the basis for certain antiprotozoal medications used to combat parasites within infected cells. The ability of a compound to generate ROS to destroy cellular macromolecular components is important because it can be modulated to achieve the maximal antiparasitic effect. ${ }^{15}$ It can therefore be postulated that quercetin-induced leishmanicidal activity occurs at least in part through the production of ROS directed selectively toward intracellular amastigotes, which might alter the cellular redox status. The linear correlation observed between the percent inhibition of the infection index and ROS production by $\mathbf{1}$ reinforces this hypothesis. A recent study by Khouri et al. demonstrated that the exposure of L. amazonensisinfected macrophages to diethyldithiocarbamate (DETC) increased the levels of superoxide anions, in turn inducing a severe reduction in the number of intracellular parasites and demonstrating the efficacy of ROS as an antimicrobial agent against intracellular parasites. ${ }^{16}$

Quercetin (1) has been shown to promote DNA cleavage by inducing topoisomerase II, leading to kDNA linearization. ${ }^{17}$ Compound 1 has also been shown to inhibit ribonucleotide reductase activity and to interfere with iron metabolism. ${ }^{18}$ However, in promastigotes of L. amazonensis, $\mathbf{1}$ has been described as a pro-oxidant, generating ROS, which leads to mitochondrial dysfunction and ultimately causes parasite death. ${ }^{19}$ In conclusion, this investigation indicates that ROS production is a part of the mechanism of action of quercetin (1) against intracellular amastigotes of L. amazonensis.

\section{EXPERIMENTAL SECTION}

Reagents. Quercetin (1) (98\% purity; lot 118K0888), Schneider's Drosophila medium, fetal calf serum, and RPMI-1640 medium were 
obtained from Sigma-Aldrich. $\mathrm{H}_{2}$ DCFDA $\left(2^{\prime}, 7^{\prime}\right.$-dichlorodihydrofluorescein diacetate) and AlamarBlue were obtained from Invitrogen Molecular Probes. All other reagents were purchased from Merck. Deionized distilled water was obtained using a Milli-Q system (Millipore Corp.) and was used in the preparation of all solutions. Endotoxin-free sterile disposable supplies were used in all experiments. Quercetin (1) was prepared in DMSO and diluted in culture medium such that the solvent concentration did not exceed $0.2 \%$ of the final solution.

Parasites. The MHOM/BR/75/LTB0016 strain of L. amazonensis was used throughout this study. The strain was isolated from a human case of cutaneous leishmaniasis in Brazil. Promastigotes of $L$. amazonensis were grown at $26{ }^{\circ} \mathrm{C}$ in Schneider's Drosophila medium ( $\mathrm{pH}$ 7.2) supplemented with $10 \%(\mathrm{v} / \mathrm{v})$ heat-inactivated fetal calf serum.

Leishmania-Macrophage Interaction Assay. L. amazonensis promastigotes were washed with phosphate-buffered saline (PBS), counted using a Neubauer chamber, and added to peritoneal macrophages at a multiplicity of infection (MOI) of 3.0. The macrophages were collected from Swiss mice (6-8 weeks old), plated in RPMI at $2 \times 10^{6}$ cells $/ \mathrm{mL}(0.4 \mathrm{~mL} /$ well $)$ in Lab-Tek eight-chamber slides, and then incubated for $3 \mathrm{~h}$ at $37{ }^{\circ} \mathrm{C}$ in an atmosphere of $5 \%$ $\mathrm{CO}_{2}$. The free parasites were removed by successive washes with RPMI. L. amazonensis-infected macrophages were then incubated in the absence or in the presence of $1(3,6$, and $12 \mu \mathrm{M})$ for $72 \mathrm{~h}$. The percentage of infected macrophages was determined using light microscopy; at least 200 cells on each coverslip were counted randomly in duplicate. The results were expressed as the infection index ( $\%$ of infected macrophages $\times$ number of amastigotes/total number of macrophages). The $\mathrm{IC}_{50}$ value was determined by logarithmic regression analysis using GraphPad Prism 5. This study was conducted in accordance with the recommendations in the Guide for the Care and Use of Laboratory Animals of the Fundação Oswaldo Cruz. The relevant protocol was approved by the Committee on the Ethics of Animal Experiments of the Fundação Oswaldo Cruz (license number: LW-7/10).

Viability Assay. Peritoneal macrophages $\left(2 \times 10^{6}\right.$ cells $\left./ \mathrm{mL}\right)$ were allowed to adhere to 96 -well tissue culture plates for $1 \mathrm{~h}$ at $37^{\circ} \mathrm{C}$ in an atmosphere of $5 \% \mathrm{CO}_{2}$. Nonadherent cells were removed by washing with RPMI-1640 medium. Then, the adherent macrophages were incubated with the indicated concentrations of 1 ( 3 to $100 \mu \mathrm{M})$ for 72 $h$. The medium was then discarded, and the macrophages were washed with RPMI-1640, after which they were incubated with AlamarBlue $(10 \% \mathrm{v} / \mathrm{v})$ for $12 \mathrm{~h}$ at $37{ }^{\circ} \mathrm{C}$ in an atmosphere of $5 \% \mathrm{CO}_{2}$. The absorbance was measured at $570 \mathrm{~nm}$ using a spectrophotometer, and the $\mathrm{IC}_{50}$ value was determined by logarithmic regression analysis using GraphPad Prism 5. The selectivity index was determined as macrophage $\mathrm{IC}_{50}$ /intracellular amastigote $\mathrm{IC}_{50}$, as previously described. ${ }^{13}$ Untreated peritoneal macrophages were lysed by the addition of $0.1 \%$ Triton X-100 as a positive control.

Measurement of ROS Levels. Intracellular ROS levels in uninfected macrophages and in L. amazonensis-infected macrophages that were treated with 1 or untreated were measured using the cellpermeable dye $\mathrm{H}_{2}$ DCFDA. $L$. amazonensis promastigotes were added to the peritoneal macrophages at an MOI of 3.0. The cells were then plated in black 96-well tissue culture plates in RPMI-1640 medium at a density of $2 \times 10^{6}$ macrophages $/ \mathrm{mL}$ and incubated for $3 \mathrm{~h}$ at $37^{\circ} \mathrm{C}$ in the presence of $5 \% \mathrm{CO}_{2}$. For the uninfected macrophages, peritoneal macrophages were plated in black 96-well tissue culture plates at a density of $2 \times 10^{6}$ macrophages $/ \mathrm{mL}$ and incubated for $3 \mathrm{~h}$ at $37^{\circ} \mathrm{C}$ in the presence of $5 \% \mathrm{CO}_{2}$. Uninfected macrophages and L. amazonensisinfected macrophages were incubated in the absence or presence of 1 (3, 6, and $12 \mu \mathrm{M})$ for $72 \mathrm{~h}$. The medium was then discarded, the macrophages were washed with Hank's Balanced Salt Solution (HBSS), and then the cells were incubated with $\mathrm{H}_{2}$ DCFDA (20 $\mu \mathrm{M})$ for $30 \mathrm{~min}$ at $37^{\circ} \mathrm{C}$. Fluorescence was measured spectrofluorometrically using an excitation wavelength of $507 \mathrm{~nm}$ and an emission wavelength of $530 \mathrm{~nm}$. For all measurements, basal fluorescence was subtracted. A positive control was obtained by adding 20 units $/ \mathrm{mL}$ glucose oxidase $+60 \mathrm{mM}$ glucose for $20 \mathrm{~min}$.
Statistical Analysis. All experiments were performed in three independent trials. The data were analyzed using Student's $t$ test or analysis of variance (ANOVA) followed by Bonferroni's post-test in GraphPad Prism 5 (GraphPad Software, La Jolla, CA, USA). The results were considered to be significant when $p \leq 0.05$. The data are expressed as the mean \pm standard error.

\section{AUTHOR INFORMATION}

\section{Corresponding Author}

*E-mail: elmo@ioc.fiocruz.br. Tel: +55(21)3865-8131.

\section{Author Contributions}

${ }^{\dagger}$ F. Fonseca-Silva and J. D. F. Inacio contributed equally to this work.

\section{Notes}

The authors declare no competing financial interest.

\section{ACKNOWLEDGMENTS}

This work was supported by the Fundação Carlos Chagas Filho de Amparo à Pesquisa do Estado do Rio de Janeiro (FAPERJ; for E.E.A-A.); Conselho Nacional de Desenvolvimento Científico e Tecnológico/Programa Estratégico de Apoio à Pesquisa em Saúde (CNPq/PAPES grant 407590/2012-9 for E.E.A-A.), and the Instituto Oswaldo Cruz/Fundação Oswaldo Cruz (IOC/Fiocruz).

\section{REFERENCES}

(1) Chawla, B.; Madhubala, R. J. Parasit. Dis. 2010, 34, 1-13.

(2) Ndjonka, D.; Rapado, L. N.; Silber, A. M.; Liebau, E.; Wrenger, C. Int. J. Mol. Sci. 2013, 14, 3395-3439.

(3) Kayser, O.; Kiderlen, A. F.; Croft, S. L. Parasitol. Res. 2003, 90 (Suppl 2), S55-S62.

(4) Bischoff, S. C. Curr. Opin. Clin. Nutr. Metab. Care 2008, 11, 733740

(5) Muzitano, M. F.; Tinoco, L. W.; Guette, C.; Kaiser, C. R.; RossiBergmann, B.; Costa, S. S. Phytochemistry 2006, 67, 2071-2077.

(6) Lapidot, T.; Walker, M. D.; Kanner, J. J. Agric. Food Chem. 2002, $50,7220-7225$

(7) Cao, G.; Sofic, E.; Prior, R. L. Free Radical Biol. Med. 1997, 22, 749-760.

(8) Miura, Y. H.; Tomita, I.; Watanabe, T.; Hirayama, T.; Fukui, S. Biol. Pharm. Bull. 1998, 21, 93-96.

(9) Mamani-Matsuda, M.; Rambert, J.; Malvy, D.; Lejoly-Boisseau, H.; Daulouede, S.; Thiolat, D.; Coves, S.; Courtois, P.; Vincendeau, P.; Mossalayi, M. D. Antimicrob. Agents Chemother. 2004, 48, 924-929.

(10) Tasdemir, D.; Kaiser, M.; Brun, R.; Yardley, V.; Schmidt, T. J.; Tosun, F.; Ruedi, P. Antimicrob. Agents Chemother. 2006, 50, 13521364.

(11) Wohrl, S.; Schnedl, J.; Auer, H.; Walochnik, J.; Stingl, G.; Geusau, A. J. Eur. Acad. Dermatol. Venereol. 2008, 22, 258-259.

(12) de Morais-Teixeira, E.; Damasceno, Q. S.; Galuppo, M. K.; Romanha, A. J.; Rabello, A. Mem. Inst. Oswaldo Cruz 2011, 106, 475478.

(13) Weniger, B.; Robledo, S.; Arango, G. J.; Deharo, E.; Aragon, R.; Munoz, V.; Callapa, J.; Lobstein, A.; Anton, R. J. Ethnopharmacol. 2001, 78, 193-200.

(14) Laughton, M. J.; Halliwell, B.; Evans, P. J.; Hoult, J. R. Biochem. Pharmacol. 1989, 38, 2859-2865.

(15) Amer, A. O.; Swanson, M. S. Curr. Opin. Microbiol. 2002, 5, 5661.

(16) Khouri, R.; Novais, F.; Santana, G.; de Oliveira, C. I.; Vannier dos Santos, M. A.; Barral, A.; Barral-Netto, M.; Van Weyenbergh, J. PLoS One 2010, 5, e14394.

(17) Mittra, B.; Saha, A.; Chowdhury, A. R.; Pal, C.; Mandal, S.; Mukhopadhyay, S.; Bandyopadhyay, S.; Majumder, H. K. Mol. Med. 2000, 6, 527-541. 
(18) Sen, G.; Mukhopadhyay, S.; Ray, M.; Biswas, T. J. Antimicrob. Chemother. 2008, 61, 1066-1075.

(19) Fonseca-Silva, F.; Inacio, J. D. F.; Canto-Cavalheiro, M. M.; Almeida-Amaral, E. E. PLoS One 2011, 6, e14666. 